\title{
A New Diagnostic Way for Behcet's Disease: Skin Prick with Self-Saliva
}

\author{
Fumio Kaneko, ${ }^{1}$ Ari Togashi, ${ }^{1}$ Erika Nomura, ${ }^{1}$ and Koichiro Nakamura ${ }^{2}$ \\ ${ }^{1}$ Institute of Dermato-Immunology and-Allergy, Southern TOHOKU Research Institute for Neuroscience, 7-115 Yatsuyamada, \\ Koriyama, Fukushima 963-8563, Japan \\ ${ }^{2}$ Department of Dermatology, Saitama Medical University, 38 Hongo, Moroyama Iruma-gun, Saitama 350-0495, Japan
}

Correspondence should be addressed to Fumio Kaneko; f.kaneko@mt.strins.or.jp

Received 11 September 2013; Accepted 18 November 2013; Published 23 January 2014

Academic Editor: Haner Direskeneli

Copyright (C) 2014 Fumio Kaneko et al. This is an open access article distributed under the Creative Commons Attribution License, which permits unrestricted use, distribution, and reproduction in any medium, provided the original work is properly cited.

\begin{abstract}
Behcet's disease (BD) is a mysterious multisystemic disorder characterized by recurrent involvement of mucocutaneous (including recurrent aphthous stomatitis; RAS), ocular, intestinal, vascular, and/or nervous system organs. Previously, the positivity of "pathergy test", which is one of the diagnostic examinations, was reported to be related to the possession of HLA-B51 gene in $\mathrm{BD}$ patients, even though the positivity is low and different from the countries. Here, instead of the ordinal pathergy test, we would like to propose the prick with self-saliva as a new diagnostic way for patients with RAS of BD based on the genetic intrinsic factors including HLA-B51 and extrinsic triggering factors. BD patients are considered to acquire the hypersensitivity against oral streptococci through the innate immune mechanism in the oral cavity. Bes-1 gene and $65 \mathrm{kD}$ of heat shock protein (HSP-65) derived from oral S. sanguinis are supposed to play important roles as extrinsic factors in BD pathogenesis. Although the prick positivity was not related to the possession of HLA-B51 gene, the method is suggested to be a significant way for BD diagnosis. The results also suggest that $\mathrm{BD}$ symptoms are due to the vascular immune responses by monocytes expressed oral streptococcal agents of the patients.
\end{abstract}

\section{Introduction}

Behcet's disease (BD) [1] is a chronic multisystematic inflammatory disorder characterized by the recurrent involvement of mucocutaneous [oral and genital ulceration, erythema nodosum (EN)-like eruption, acne-like eruption, etc.], ocular, vascular, digestive, and/or nervous system organs. Although the actual etiology of $\mathrm{BD}$ is still unclear, the pathogenesis has been generally clearer by the etiological research based on the genetic intrinsic factors and immunological reactions to the extrinsic triggering factors in an environmental agent [2-14]. As one of the triggering factors, the oral unhygienic condition may be suspected, because periodontitis, decayed teeth, chronic tonsillitis, and so forth are frequently noted in the oral cavity of $\mathrm{BD}$ patients $[9,10]$. The infectious triggering factors are suspected to be many organisms including streptococci, herpes simplex viruses (HSVs), Saccharomyces fermentans, Borrelia burgdorferi, Helicobacter pylori, Escherichia coli, Staphylococcus aureus, Mycoplasma fermentans, and mycobacterium [11].
The proportion of Streptococcus sanguinis (S. sanguinis), which was previously recognized as species of the genus Streptococcus named "S. sanguis," was significantly high in the oral bacterial flora of $\mathrm{BD}$ patients in comparison with those of healthy controls [12-14]. Most of the patients tend to acquire hypersensitivity against streptococci in their oral bacterial flora, as previously demonstrated that much stronger cutaneous reactions were seen by the prick with streptococcal antigen than those by "Pathergy test" $[8,9,15,16]$. Non-BD patients with recurrent aphthous stomatitis (nonBD-RAS) were also having the hyperreactivity as reported by Graykowski et al. in the 1960s [17]. In vitro system, inflammatory cytokines, interleukin (IL)-6, and interferon (IFN) $-\gamma$ were produced from peripheral blood mononuclear cells (PBMCs) of BD patients, which were stimulated by streptococcal antigen [18], and the serum-antibody titers against streptococci were also elevated in BD patients [19]. The peptides of $65 \mathrm{kD}$ of heat shock protein (HSP-65) derived from streptococci show considerable homology with those 


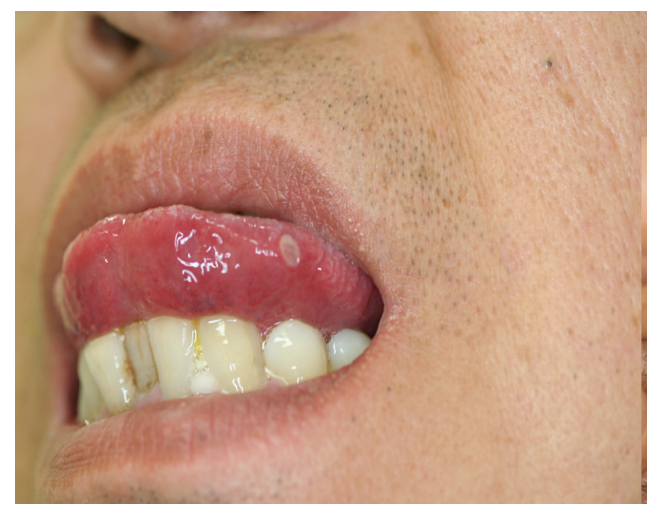

(a)

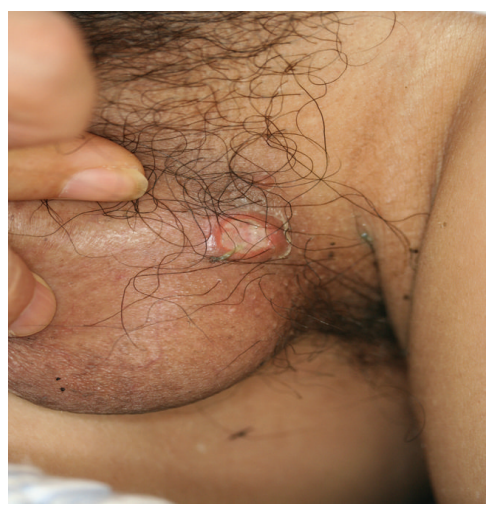

(b)

FIGURE 1: Oral aphtha and genital ulcerations seen in a male BD patient with neuropathy (55 M YY in Table 1). (a) Oral ulcer round and punched-out shaped on the tongue. (b) Genital ulcer shaped like oral ulcer.

of the human HSP-60 which appeared as counterpart after streptococcal infection [20-22].

Here, an attempt to review on the mucocutaneous manifestations clinically seen in $\mathrm{BD}$ patients was done in the connection with the genetic intrinsic and extrinsic triggering factors. We would like to take up a new diagnostic way for BD using self-saliva prick instead of the ordinal "Pathergy test" which seems to be low positive in BD patients.

\section{Mucocutaneous Involvements}

2.1. Aphthous Ulceration. RAS generally starts as an initial symptom in BD patients since their childhood and/or youth and other mucocutaneous symptoms follow after RAS [2325] (Figures 1(a) and 1(b)). The oral aphthous ulceration punch-out shaped occurs with pain on the tongue, buccal mucosa, gingival, and lip and it continues around a week in $\mathrm{BD}$ patients. The clinical features of the oral ulcers is divided as minor, major, herpetiform, and the combined types depending on the lesional size and shapes. Non-BDRAS is a very common disorder due to trauma, some viral and/or bacterial infections except for patients with $\mathrm{BD}$, and other autoimmune diseases; because it is known that $20 \%$ of the general population is affected in the world [26]. On the other hand, nearly $100 \%$ of BD patients are associated with RAS as the initial symptom as aphthous ulceration. The biopsy specimen of aphthous ulcer lesion from a BD patient revealed a reaction-like the antibody dependent cell mediated cytotoxicity that the epithelial cells surrounded by neutrophils and lymphoid cells look like leaves falling down from the mucous epithelial layer (Figures 2(a) and 2(b)). These epithelial cells are stained with IgM and HLA-DR and are surrounded by $\mathrm{T}$ cells in the immunohistological findings and in addition antistreptococcal antibody was also stained on the cell membrane of the epithelium $[15,27]$. However, it is histologically difficult to differentiate aphthous ulceration of BD patient from non-BD-RAS patients.

2.2. Genital Ulcer. The clinical features of genital ulceration are generally shaped as similar to oral aphthous ulceration in $\mathrm{BD}$ patients (Figure 1(b)) and in young female a genital ulceration suddenly occurs as the initial symptom of $\mathrm{BD}$ as Lipschutz ulceration [28], although it was reported to be related to Epstein-Barr viral infection [29]. About more than $50 \%$ of BD patients are found to be associated with genital ulceration (female, $55.5 \%$; male, $58.7 \%$ ); that is, ulcers occur on vulva $(66.1 \%)$, vaginal mucosa $(35.7 \%)$, anus (9.6\%), cervix (4.1), and groin area $(0.8 \%)$ in female patients and on the penis $(46.5 \%)$, scrotum $(38.5 \%)$, anus $(9.2 \%)$, and groin area $(5.0 \%)$ in male patients $[23,25]$.

2.3. EN-Like Eruption. More than $50 \%$ of $\mathrm{BD}$ patients is reported to be associated with EN-like eruption on the legs [23-25, 30], which relatively looks smaller indulation than that of non-BD patients (Figure 3(a)). The histology is generally vascular reaction infiltrated by lymphoid cells, so-called lymphocytic vasculitis, in the dermis and septal panniculitis in the subcutaneous fatty tissue (Figure 3(b)). In acute phase, however, vasculitis surrounded by neutrophils is also able to be recognized. Immunofluorescence technique revealed deposits of $\operatorname{IgA}$, IgM, and complement in the vascular walls and the similar findings can be seen in the reactive site by pathergy test [31-33]. Streptococcal related materials can also be detected in the vascular walls by use of antistreptococcal antibody (Figure 3(c)) [9, 15, 27]. Recently, Cho et al. $[34,35]$ have demonstrated that IgA and IgM deposited at the lesional vascular walls targeted against human nuclear ribonucleoprotein (hnRNP) A2/B1 of the endothelial cells in BD patients whose serum IgA and IgM also reacted with S. sanguinis and HSP-65/60.

2.4. Other Cutaneous Disorders. Acne-like eruption due to perifolliculitis repeatedly appears on the upper body of BD patients and subcutaneous thrombophlebitis, so-called "thrombophlebitis migrans," is suddenly noticed on the lower extremities. Rarely, the follicular lesions may develop to a large ulceration like "pyoderma gangrenosum" on the extremities. Some male BD patients may have a sudden pain and edema of the scrotum due to epididymitis. 


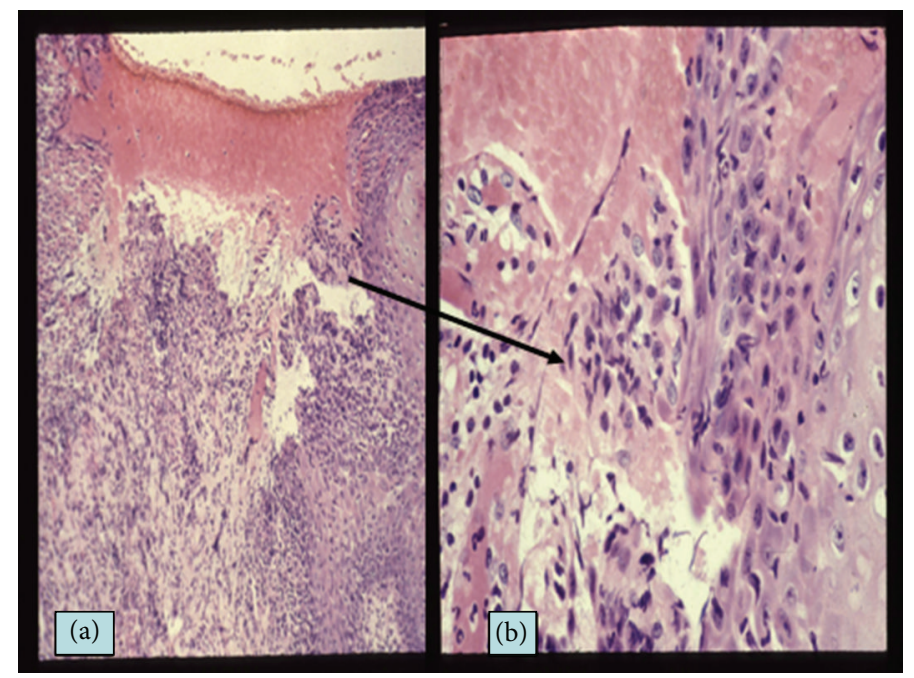

FIGURE 2: Histology of aphthous ulceration of a BD patient. (a) Aphthous ulcer of the lip defecting the epithelial layer (HE, $\times 100$ ). (b) Magnified feature of the ulcer edge of the epithelial layer. The epithelial cells are surrounded by inflammatory infiltrates like "Rosetta formation."

Histology and immunohistology by antistreptococcal group $\mathrm{D}$ antibody in the lesions of Behcet's disease (Kaneko et al., Br. J. Dermatol., 1985)
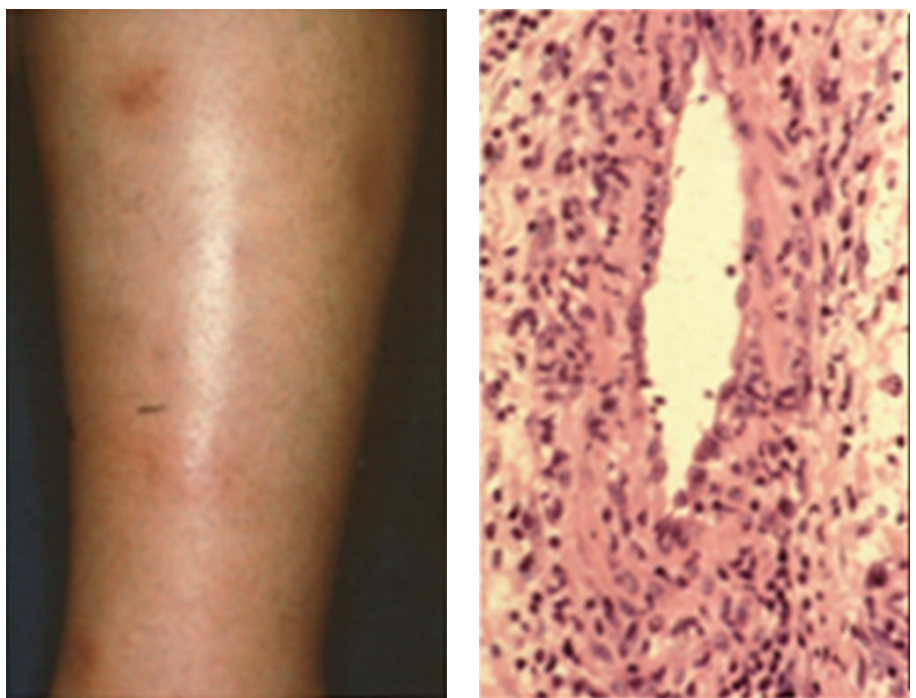

Fukushima Medical University School of Medicine, Department of Dermatology

(a) (b)

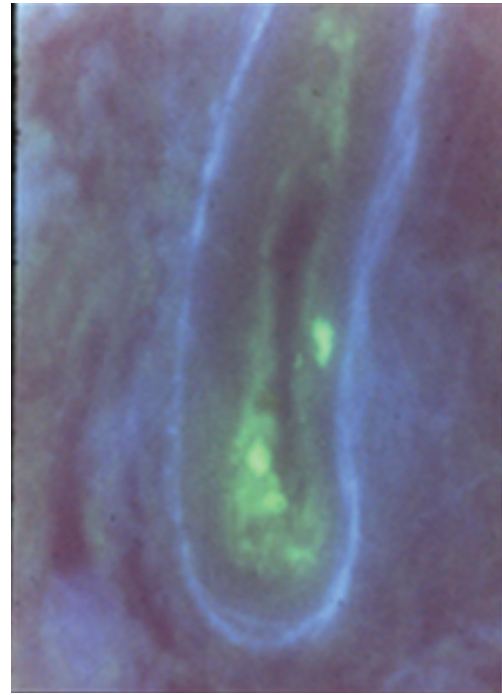

(c)

FIGURE 3: EN-like eruption and the histology and immunohistology. (a) EN-like eruption on the lower legs of a BD patient. (b) Vasculitis infiltrated by lymphoid cells and neutrophils (HE, 400x). (c) Deposits of streptococcal antigen adhering to the vascular wall (direct immunofluorescence, $\times 400$ ).

\section{Pathergy Test and Oral Streptococci}

The diagnosis of $\mathrm{BD}$ is not thought to be difficult for the clinically typical cases who are based on the diagnostic criteria by Japanese and/or International Study Group [24, 36 , except for the atypical cases without the main mucocutaneous symptoms including RAS. Pathergy test, which is a nonspecific cutaneous hypersensitive reaction showing around $2 \mathrm{~mm}$ pustule $24-48 \mathrm{~h}$ after $20 \mathrm{G}$ syringe needle stick, has been thought to be helpful for making a diagnosis of $\mathrm{BD}$ for long time, because the phenomenon has been believed as a unique feature for $\mathrm{BD}$. The reactive conditions seem to be varied by the technical method and generally the high positivity is found in Mediterranean and Middle East countries [30]. The reactivity of the "pathergy test" is suggested to be correlated with HLA-B51 in Mediterranean countries [37] and it is one of diagnostic criteria by International Study Group of BD [36]. On the other hand, in the Japanese BD diagnostic criteria "pathergy test" is considered as one of the diagnostic references $[23,24]$. However, its positivity in $\mathrm{BD}$ 
TABLE 1: Self-salivary prick test in patients with aphthous ulceration and controls.

\begin{tabular}{|c|c|c|c|c|c|}
\hline Patients & Age, sex (initials) & $\begin{array}{l}\text { Prick test } \\
\text { (after } 48 \text { h) }\end{array}$ & Small pustule & SS-prick & CS-prick \\
\hline Neuro BD & $55 \mathrm{M}$ YY & $11 \times 15 \mathrm{~mm}$ & + & nd & - \\
\hline \multirow{7}{*}{ Incomplete } & $33 \mathrm{~F} \mathrm{AT}^{*}$ & $22 \times 22$ & - & - & - \\
\hline & $26 \mathrm{~F} \mathrm{MN}^{*}$ & $10 \times 10$ & + & $+\operatorname{dot}$ & - \\
\hline & $27 \mathrm{M}$ TG & $11 \times 12$ & + & $+\operatorname{dot}$ & - \\
\hline & $47 \mathrm{M}$ YT & $10 \times 13$ & + & $+\operatorname{dot}$ & - \\
\hline & $36 \mathrm{~F} \mathrm{AN}^{*}$ & $5 \times 10$ & - & nd & - \\
\hline & $46 \mathrm{M} \mathrm{KH}$ & $10 \times 10$ & - & - & - \\
\hline & $17 \mathrm{~F} Y \mathrm{~T}$ & $5 \times 5$ & - & - & - \\
\hline Complete & $23 \mathrm{M} \mathrm{OO}^{*}$ & $10 \times 10$ & + & - & - \\
\hline \multirow{5}{*}{$\begin{array}{l}\text { Recurrent aphthous stomatitis } \\
\text { (non-BD RAS) }\end{array}$} & $24 \mathrm{~F} Y N$ & $8 \times 10 \mathrm{~mm}$ & - & - & - \\
\hline & 28 F YS & $8 \times 4$ & - & - & - \\
\hline & 32 F YN & - & - & nd & - \\
\hline & $29 \mathrm{M} \mathrm{ON}$ & - & - & nd & - \\
\hline & 28 F MS & $3 \times 5$ & - & - & - \\
\hline \multirow{2}{*}{$\begin{array}{l}\text { Disease controls } \\
\text { non-BD EN }\end{array}$} & $39 \mathrm{~F} \mathrm{KY}$ & - & - & nd & - \\
\hline & $61 \mathrm{~F} \mathrm{MF}$ & - & - & - & - \\
\hline Viral aphthosis (3) & & - & - & nd & - \\
\hline Healthy controls (6) & & - & - & - & - \\
\hline
\end{tabular}

BD: Behcet's disease; EN: erythema nodosum; F: female; M: male; dot: small spot; +: positive; -:negative. S-prick: prick with self-saliva; SS-prick: prick with sterilized self-saliva; CS: prick with saline; nd: not done. The clinical type of BD is followed by the Japanese BD classification. ${ }^{*}$ Same cases in Table 2.

patients seems to be chronologically lower to less than $40 \%$ of $\mathrm{BD}$ patients seen in $2007 \mathrm{~s}$, though more than $70 \%$ of the patients exhibited positive to the pathergy test in 1970s. The positivity by the test is also different from the prevalence in the countries, as mentioned [38-40]. It is of interest that the surgical cleaning of the forearm before needle prick reduced the prevalence of the "pathergy reaction" [41], suggesting that the positive reaction might be a cutaneous response to some bacteria living on the surface of the skin. In our all cases shown in Tables 1 and 2 none of cutaneous reactions were found 24-48 hours after venipuncture for the clinical examinations using syringe with $22 \mathrm{G}$ needle, because, before the venipuncture, their forearm was cleaned.

As it is known that many kinds of bacteria are contained in our saliva, we tried to incubate saliva form a BD patient using Mitis-Salivarius (MS) agar which streptococci are selectively grown. The result showed many oral streptococci grew up from pure saliva (Figure 4(a)) and that no bacteria grew from the sterilized saliva by use of a syringe micromembrane filter (Figure 4(b)). Then, instead of conventional "pathergy test," we tried to prick with self-saliva in which oral bacteria including streptococci are ordinary contained to the forearms of $\mathrm{BD}$ patients for diagnosis using a Lancetter with a tiny stick (OY ALGO AB Espoo/Esbo, Sweden) because the patients have hypersensitivity to oral streptococci, as described previously. The results revealed more than $90 \%$ of $10 \mathrm{BD}$ patients showed erythematous reaction by stick with self-saliva and that a tiny spot or no reaction was seen by the prick with microfilter-sterilized saliva and control saline (Figure 5, Table 1) [42]. The results also suggest that oral streptococci are playing an important role in the pathogenesis of the RAS of BD patients and that the salivary prick is able to make a differentiation of BD from non-BD disorders. The reaction and severity to self-saliva prick was not related to the possession of the HLA-B51 gene in BD patients (Table 2).

\section{HLA Genotyping of BD and Streptococcal Infection}

HLA-B51 is supposed to be a highly associated genetic marker of BD patients from many different ethnic groups including European, Mediterranean, and Asian people and $\mathrm{BD}$ has several unique epidemiologic features from Southern Europe to Japan along "the old silk route" $[2,4,5,44]$. The appearance of $\mathrm{BD}$ lesions is not directly correlated with HLA-B51 in the immunological background of the patients, but it was recently found that HLA-B51-restricted cytotoxic $\mathrm{T}$ lymphocytes (CTLs) and $\gamma \delta \mathrm{T}$ cells played some roles in correlation with the stressed target tissues expressing major histocompatibility complex class I-related gene A (MICA) in $\mathrm{BD}$ pathogenesis. When the transmembrane-MICA located nearly at the HLA-B51 gene is expressed preferentially on epithelial and endothelial cells by stress, they seem to be the candidates for the HLA-B51-restricted CTLs response and MICA expressed on the stressed epithelium and endothelium which are considered to be the ligand for activating natural killer (NK) cells with NKG2D molecule, $\gamma \delta$ T cells, and $\mathrm{CD}^{+}$ T cells as CTLs [45]. Regarding NK cell activation, inhibitory CD34/NKG2A and activating CD94/NKG2C molecules are 
TABLE 2: Self-salivary prick test in BD patients with or without HLA-B51.

\begin{tabular}{|c|c|c|c|c|c|}
\hline \multirow{2}{*}{ Type of BD (Japanese classification) } & \multirow{2}{*}{ Patients (initials) } & \multicolumn{3}{|c|}{ Prick test (mm) } & \multirow{2}{*}{ HLA-B51 } \\
\hline & & S & SS & CS & \\
\hline Complete type & $23 \mathrm{M} \mathrm{OO}^{*}$ & 10 & - & - & $+(\mathrm{B} 51)$ \\
\hline \multirow{13}{*}{ Incomplete type } & $40 \mathrm{M} \mathrm{HG}$ & 10 & 7 & - & $+(\mathrm{B} 51,01,01)$ \\
\hline & $31 \mathrm{~F}$ MA & 30 & 7 & - & $+(\mathrm{B} 51,40)$ \\
\hline & $42 \mathrm{~F} \mathrm{MK}$ & 7 & 4 & - & $+(\mathrm{B} 51,46, \mathrm{DR} 4,8)$ \\
\hline & 34 F MY & 26 & 5 & - & $-(\mathrm{B} 35,48)$ \\
\hline & $36 \mathrm{~F} \mathrm{AN}^{*}$ & 10 & - & - & $-(\mathrm{B} 44,03,01)$ \\
\hline & 33 F YK & 10 & - & - & - \\
\hline & $37 \mathrm{~F} \mathrm{AT}^{*}$ & 22 & - & - & $-(\mathrm{B} 40,48)$ \\
\hline & $30 \mathrm{~F} \mathrm{MN}^{*}$ & 10 & - & - & - \\
\hline & 35 M YI & 10 & nd & - & $-(\mathrm{B} 15,35)$ \\
\hline & $37 \mathrm{~F} \mathrm{HT}$ & 4 & - & - & $-(\mathrm{B} 40,44)$ \\
\hline & $36 \mathrm{M} \mathrm{MK}$ & 4 & 3 & - & $-(\mathrm{B} 35,44)$ \\
\hline & $35 \mathrm{M} \mathrm{KF}$ & 7 & 2 & - & $-(\mathrm{B} 46,54)$ \\
\hline & 35 F YO & 14 & - & - & $-(\mathrm{B} 07,02,01)$ \\
\hline
\end{tabular}

F: female; M: male; S: self-saliva; SS: filtered sterilized saliva; CS: control saline; +: positive; -: negative; nd: not done. ${ }^{*}$ Same cases in Table 1.

alternatively expressed on $\mathrm{NK}, \mathrm{CD} 4^{+} \mathrm{CD} 8^{+} \mathrm{T}$ cells, as indicating an imbalance in cytotoxic activity in BD patients [46], although the function of NK cells is supposed to be downregulated in the active stage and to be up-regulated in the remission of $\mathrm{BD}$ patients [47]. The excessive $\mathrm{CD} 4^{+} \mathrm{T}$ cells activated by inflammatory cytokines including interferon (IFN)- $\gamma$, IL-12, and IL-23 were altered to Th17 cells and IL17 which might be released from them in the BD lesions [48].

It is considered that HSP-65/60 derived from microorganism including $S$. sanguinis and from human tissues, which is detected in the oral mucosal and skin lesions of BD patients $[20,21]$, also becomes a stress-inducible factor in connection with MICA*009 expression. Generally, antigen presenting cells (APCs), which produce IL-12 in correlation with Th1 type immune-reaction, are thought to be activated in BD patients with HLA-B51 in active stage, as indicated by Yasuoka et al. [45]. However, we have obtained the results that PBMCs from BD patients without HLA-B51 gene can be significantly stimulated by $S$. sanguinis antigen in the expression of IL$12 \mathrm{p} 40 \mathrm{mRNA}$ and increasing of protein level in connection with IL-12p70 (70 kDa composed of p35 and p40 subunits) rather than those of the patients with HLA-B51 [51]. It has been suggested that antibacterial host response in T cell type immunity mediated by IL-12 is much stronger in HLA-B51negative $\mathrm{BD}$ patients. The skin response severity by the prick with oral streptococci of self-saliva seemed to be unrelated to the HLA-B51 gene as seen in Table 2.

\section{Hypersensitivity against $S$. sanguinis}

Generally, the oral health is impaired in BD patients [8-13], which seems to be associated with the disease severity [10]. Although there are a number of the triggering factors for $\mathrm{BD}$ in environmental agent, the predisposition of $\mathrm{BD}$ patients may be correlated with streptococcal infection as one of the factors, because the uncommon serotype oral S. sanguinis is

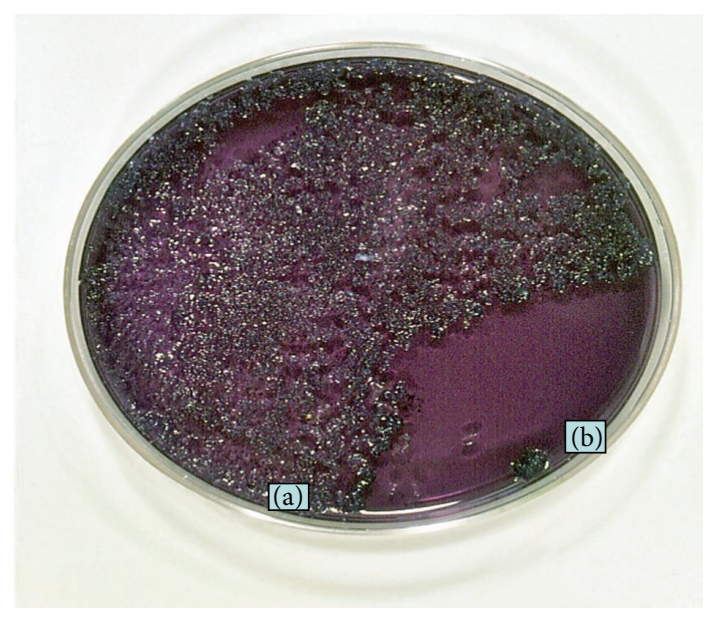

FIGURE 4: Incubation of saliva of a BD patient using MS (mitis and salivarius) agar in which oral streptococci are selectively grown. (a) Oral streptococci grew from saliva in 5 day. (b) Area of sterilized saliva using syringe micromembrane filter.

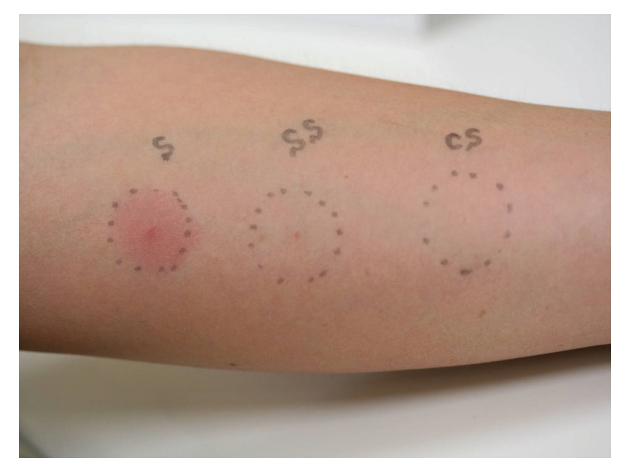

FIGURE 5: Prick test with self-saliva using Lancetter (33 F AT in Table 1). The skin reactions were observed 48 hours after prick. S: self-saliva; SS: sterilized saliva using syringe-filter with $0.2 \mu \mathrm{m}$ pores; CS: control saline. 
Bes-1 DNA fragment encoding Streptococcus sanguinis in the mucocutaneous lesions

Patients

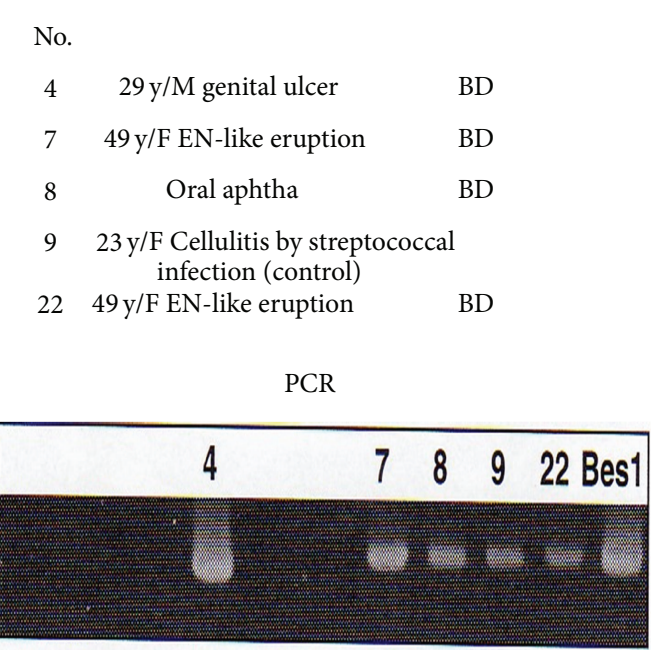

(a)

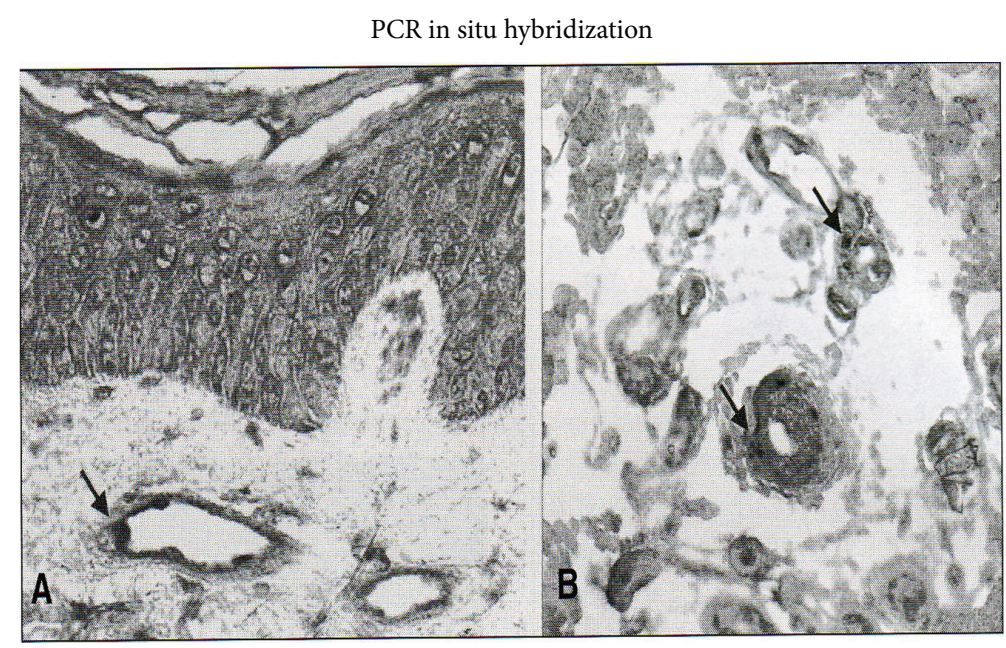

(b)

FIgURE 6: Bes-1 gene expression in the mucocutaneous lesions of patients with Behcet's disease (BD) [43]. (a) Three of 11 BD patients were positive for Bes-1 DNA in the lesions including aphthous and genital ulcerations and erythema nodosum (EN)-like eruption by amplified polymerase chain reaction (PCR) using the primers: Bes-1-1 (5'-TAATAACCCTGACCAAGCCTA- $\left.3^{\prime}\right)$ and Bes-1-2 (5'CCCTTTCAAAAGTCATAAATC- $3^{\prime}$ ) encoding S. sanguinis. (b) In these positive lesions, Bes-1 DNA was also detected in the cytoplasm of monocytes adhering to the vascular walls and infiltrated around the vessels by PCR in situ hybridization.

significantly increased in $\mathrm{BD}$ patients compared with healthy and disease controls [11-15]. The antibodies against $S$. sanguinis in sera from BD patients showed cross reactivity with the some synthetic peptides of HSP-65 derived from S. sanguinis [52-54]. The patients show strong delayed type cutaneous hypersensitivity reactions against streptococcal antigens in skin tests $[8,9,15]$ and sometimes the BD symptoms were provoked by skin injection of the antigens [16]. Because aphthous ulceration can be also induced by a prick with streptococcal antigen on the oral mucous membrane of a BD patient [9], the appearance of aphthous ulceration is considered to be based on the hypersensitive reaction against $S$. sanguinis which may be traumatically penetrated into the oral membrane of BD patients. Isogai et al. [53] demonstrated that the symptoms mimicking $\mathrm{BD}$ appeared in germ-free mice when S. sanguinis from BD patients was inoculated into their oral tissue damaged by heat shock and/or mechanical stress. This report suggests that the immunization with $S$. sanguinis through the oral membrane route elicits $\mathrm{BD}$-like symptoms in the animal model as seen in BD patients who carry S. sanguinis as the pathogenic microorganism in their oral cavity. In order to find polymerase chain reaction (PCR) targeting Bes-1 gene in BD lesions using 2 distinct primer sets (peptides, 229-243, and 373-385) encoding S. sanguinis (serotype KTH-1) which was prepared by Yoshikawa et al. [54], we recognized that Bes-1 DNA was present in various mucocutaneous lesions including oral and genital ulcerations and EN-like lesions. The PCR in situ hybridization also revealed that Bes-1 DNA was expressed in the cytoplasm of inflammatory infiltrated monocytes adhering the vascular walls in mucocutaneous lesions (Figure 6) [43]. In contrast, we failed to detect DNAs of HSV-1, HSV-2, cytomegalovirus, human herpes virus (HHV)-6, and HHV-7 in the lesions by PCR [55], although HSV infection has been speculated as etiologically important since the report of Behcet [1]. Interestingly, the amino acid sequence of the peptides of Bes1 (229-243 and 373-385) shows more than 60\% similarity to the human intraocular ganglion peptide, $B r n-3 b$ which is a subfamily of POU (pit-Oct Unc) domain factors containing $B r n-3 a$ and Brn-3c [56]. The peptide of Bes-1 (229-243) was also found to be correlated with the peptide of HSP-60 (336351) [54]. Recently, it has been found that the peptide of Bes-1 (337-385) stimulated PBMCs of BD patients which produced IFN- $\gamma$ and IL-12, though the cellular proliferation of the stimulated PBMCs was not observed [57]. These results suggest that Bes-1 derived from oral S. sanguinis might be an inducer for the possible retinal and neural involvement in $\mathrm{BD}$ patients.

\section{HSPs and BD Pathogenesis}

Antibodies against the HSP peptides derived from bacteria including $S$. sanguinis are found in aphthous ulceration and serum of BD patients [58], though HSP specific antibodies and $\mathrm{T}$ cells are considered to play a complicated role in the pathogenesis of human autoimmune diseases [59]. It is speculated that HSPs trigger both innate and adaptive immune mechanisms in BD. On the other hand, the therapeutic approaches involving HSP immunomodulation may be available as "oral toleration" using the peptide of HSP (336-351) 


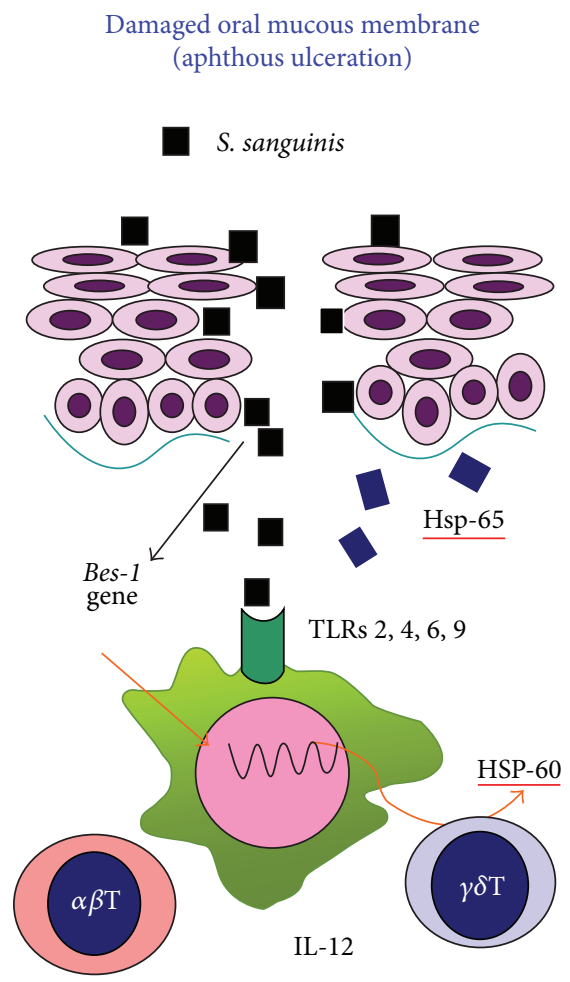

(a)

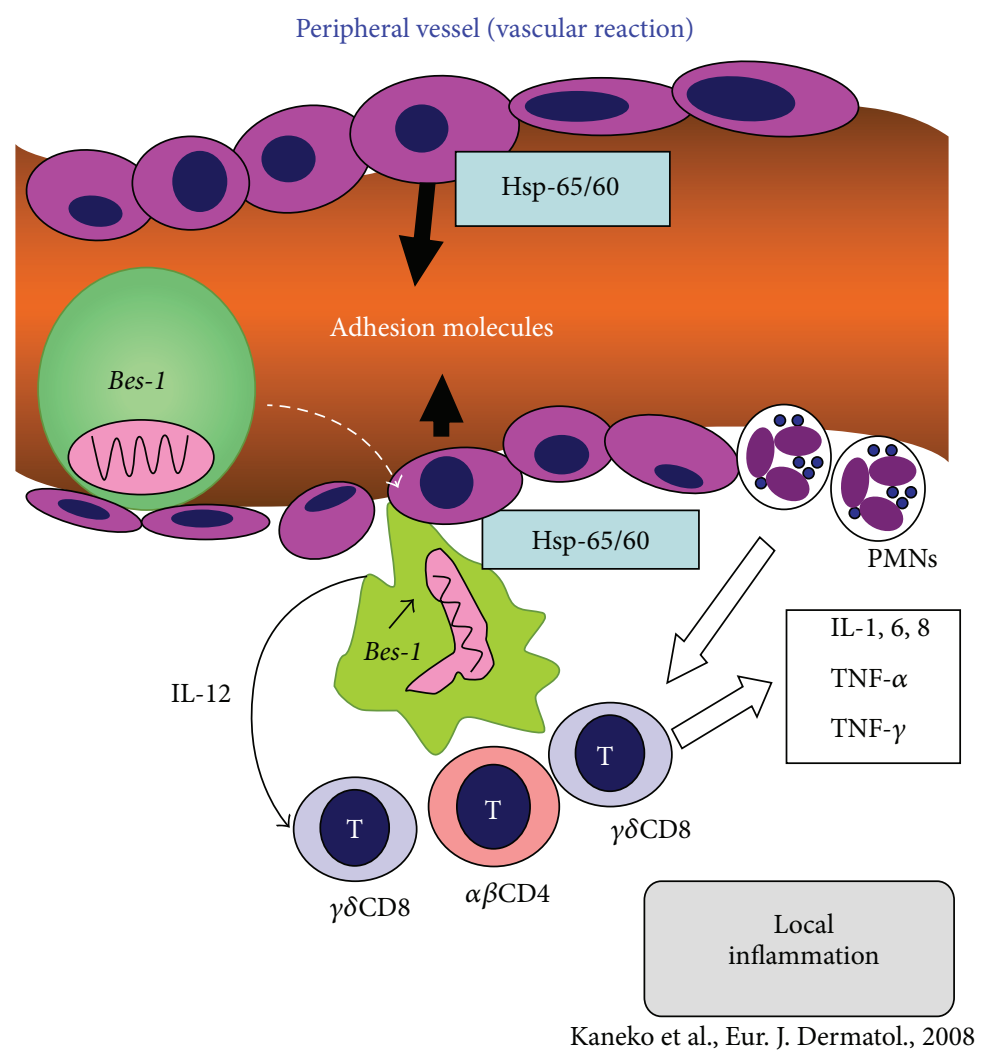

(b)

FIGURE 7: Hypothesis of the mechanisms in the appearance of various lesions of BD patients [49, 50]. (a) The antigen presenting cells (APCs) (macrophages and/or dendritic cells) immunized by S. sanguinis agents though TLRs in the oral cavity might be carried to the peripheral regions. (b) If the APCs in the blood flow adhered to the impaired and/or MICA and adhesion molecules expressed endothelial cells of vascular wall, the immunological reaction might be appeared as BD lesion.

linked to recombinant cholera toxin B for BD patients with advanced uveitis, as demonstrated by Stanford et al. [60]. In order to understand the suppressive mechanisms of the cytokine production in PBMCs from active BD patients, we tried to find the binding sites of the peptides on monocytes by cDNA chips (Gene Chip; Human Genome) using NOMO-1 cells (human macrophage cell line) activated by S. sanguinis antigen and they were incubated with the peptides. It was found that although the expression of IL-8, IL-16, IL-13R, and IL-17R was decreased after incubation with HSP-65 peptides (LO1 and UK), respectively, LO2 (480-499) did not decrease IL-8 production. CD58 (lymphocyte functionassociated antigen-3) molecule and/or FK506 binding protein were highly expressed on the cell membrane by LO1 (249-264) and UK (311-326) [61, 62].

\section{Toll-Like Receptor (TLR) Expression in the Innate Immunity}

Regarding the recognition system for the microorganism antigens in humans, 10 numbers of TLR family are supposed to act as innate immune receptors by binding of particular structures present on bacteria, viruses, fungi, and so forth
[63]. Although generally TLRs are weakly detectable in various human tissues with varying levels, the TLR expression of the organs involved in immune response and exposed to environment is found to be significantly stronger [64]. TLR-3 [ds RNA] and TLR-6 [mycoplasma, staphylococci, etc.] are also reported to be enhanced in expression on neutrophils and monocytes of BD patients, when stimulated by HSP60 and S. sanguinis antigen [65]. In the oral ulcer lesion, expression of TLR-9 [unmethylated CpG DNA, bacteria, and virus] has been found recently [66]. These findings suggest that innate immune system contributes the acquisition of hypersensitivity against oral $S$. sanguinis as the extrinsic factor in the pathogenesis of $\mathrm{BD}$.

\section{Oral Aphthous Ulceration and Systemic Symptoms}

BD symptoms are characterized by vascular involvements showing swollen endothelial cells of the microarteries infiltrated by inflammatory monocytes and a few neutrophils histologically, as so-called "vascular reaction" seen in ENlike eruption and other lesions $[15,31,67,68]$. The strong hypersensitivity reaction against $S$. sanguinis agents $[8,9,15$, $16,18]$ which might be gained by antigen present cells (APCs) 
through the innate immune mechanism can be suspected as the extrinsic triggering factor in the pathogenesis of $\mathrm{BD}$. In the treatment by antibiotics for the involvement of oral $S$. sanguinis, especially minocycline, which not only reduces the growth of streptococci but also suppresses IL-1 $\beta$ and IL-6 production from $\mathrm{T}$ cells inflamed, was clinically effective for aphthous ulceration, acne-like eruption and EN-like lesion in BD patients [9]. Other study also showed that combination therapy, colchicine and benzathine penicillin, was effective to suppress BD symptoms compared to colchicine monotherapy [69, 70]. Although Kaneko et al. [49] and others [5-7] have already reviewed on the role of infectious agents in $\mathrm{BD}$ pathogenesis, we also dare to propose the hypothesis that after Bes-1 gene taken in the cytoplasm of APCs through the TLRs in the oral cavity, the APCs, which are expressing the streptococcal antigen, produce HSP-65/60, as demonstrated by Deniz et al. [58]. If these APCs are curried in the blood flow to the impaired and/or MICA expressed endothelium of the vessels in correlation with HSP-65/60, VEGF, adhesion molecules, and so forth, $\mathrm{BD}$ lesions might be induced by the "vascular reaction" and/or "lymphocytic vasculitis" as the immunological reaction by the APCs expressing S. sanguinis antigen. Then, the relationship between oral ulceration and the systemic symptoms might be considered as illustrated in Figure 7. From the viewpoint, it is considerable that the positivity of the prick with self-saliva is high for BD patients $[49,50,62]$. So, we would like to propose a new diagnostic way for $\mathrm{BD}$ and differentiation from non-BD patients and/or non-BD RAS patients.

\section{Conflict of Interests}

The authors declare that there is no conflict of interests regarding the publication of this paper.

\section{Acknowledgments}

We deeply appreciate that our studies were supported by the Grants from Japanese Behcet's Disease Research Committee of the Ministry of Health, Labor and Welfare.

\section{References}

[1] H. Behcet, "Uber rezidivierende, aphthous durch ein Virus verursachte Geschwuere am Mund, am Auge und an den Genitalien," Dermatologische Wochenschrift, vol. 105, pp. 1152-1157, 1937.

[2] A. Altenburg, N. Papoutsis, H. Orawa, P. Martus, L. Krause, and C. C. Zouboulis, "Epidemiology and clinical manifestations of Adamantiades-Behcet disease in Germany-current pathogenetic concepts and therapeutic possibilities," Journal of the German Society of Dermatology, vol. 4, no. 1, pp. 49-66, 2006.

[3] E. Alpsoy, C. Zouboulis, and G. E. Ehrlich, "Mucocutaneous lesions of Behcet's disease," Yonsei Medical Journal, vol. 48, no. 4, pp. 573-585, 2007.

[4] S. Ohno, M. Onguchi, S. Hirose, H. Matsuda, A. Wakisaka, and M. Aizawa, "Close association of HLA-Bw51 with Behcet's disease," Archives of Ophthalmology, vol. 100, no. 9, pp. 14551458, 1982.
[5] C. C. Zouboulis and T. May, "Pathogenesis of AdamantiadesBehcet's disease," Medical Microbiology and Immunology, vol. 192, no. 3, pp. 149-155, 2003.

[6] A. Karaycian and C. C. Zouboulis, "An update on Behcet's disease," Journal of the European Academy of Dermatology and Venereology, vol. 21, pp. 1-10, 2007.

[7] I. Krause and A. Weinberger, "Behcet's disease," Current Opinion in Rheumatology, vol. 20, pp. 82-87, 2008.

[8] F. Kaneko, T. Kaneda, O. Ohnishi et al., "Infection allergy in Behcet's disease," Japanese Journal of Allergology, vol. 27, pp. 440-450, 1978.

[9] F. Kaneko, N. Oyama, and A. Nishibu, "Streptococcal infection in the pathogenesis of Behcet's disease and clinical effects of minocycline on the disease symptoms," Yonsei Medical Journal, vol. 38 , no. 6 , pp. 444-454, 1997.

[10] G. Mumcu, T. Ergun, N. Inanc et al., "Oral health is impaired in Behcet's disease and is associated with disease severity," Rheumatology, vol. 43, no. 8, pp. 1028-1033, 2004.

[11] M. Galeone, R. Colucci, A. M. D'Erme, S. Moretti, and T. Lotti, "Potential infectious etiology of Behcet's disease," Pathology Research International, vol. 2012, Article ID 595380, 4 pages, 2012.

[12] K. Yokota, S. Hayashi, Y. Araki et al., "Characterization of Streptococcus sanguis isolated from patients with Behcet's disease," Microbiology and Immunology, vol. 39, no. 9, pp. 729-732, 1995.

[13] E. Isogai, S. Ohno, K. Takashi et al., "Close association of Streptococcus sanguis uncommon serotypes with Behcet's disease," Bifidobacteria Microflora, vol. 9, pp. 27-41, 1990.

[14] E. Isogai, S. Ohno, S. Kotake et al., "Chemiluminescence of neutrophils from patients with Behcet's disease and its correlation with an increased proportion of uncommon serotypes of Streptococcus sanguis in the oral flora," Archives of Oral Biology, vol. 35, no. 1, pp. 43-48, 1990.

[15] F. Kaneko, Y. Takahashi, Y. Muramatsu, and Y. Miura, "Immunological studies on aphthous ulcer and erythema nodosumlike eruptions in Behcet's disease," The British Journal of Dermatology, vol. 113, no. 3, pp. 303-312, 1985.

[16] Y. Mizushima, T. Matsuda, K. Hoshi, and S. Ohno, "Induction of Behcet's disease symptoms after dental treatment and streptococcal antigen skin test," Journal of Rheumatology, vol. 15, no. 6, pp. 1029-1030, 1988.

[17] E. A. Graykowski, M. F. Barile, W. B. Lee, and H. R. Stanley Jr., "Recurrent aphthous stomatitis. Clinical, therapeutic, histopathologic, and hypersensitivity aspects," The Journal of the American Medical Association, vol. 196, no. 7, pp. 637-644, 1966.

[18] S. Hirohata, H. Oka, and Y. Mizushima, "Streptococcal-related antigens stimulate production of IL6 and interferon $-\gamma$ by T cells from patients with Behcet's disease," Cellular Immunology, vol. 140, no. 2, pp. 410-419, 1992.

[19] K. Yokota, S. Hayashi, N. Fuji et al., "Antibody response to oral Streptococci in Behcet's disease," Microbiology and Immunology, vol. 36, no. 8, pp. 815-822, 1992.

[20] T. Lehner, "The role of heat shock protein, microbial and autoimmune agents in the etiology of Behcet's disease," International Reviews of Immunology, vol. 14, no. 1, pp. 21-32, 1997.

[21] S. Kaneko, N. Suzuki, N. Yamashita et al., "Characterization of T cells specific for an epitope of human $60-\mathrm{kD}$ heat shock protein (hsp) in patients with Behcet's disease (BD) in Japan," Clinical and Experimental Immunology, vol. 108, no. 2, pp. 204-212, 1997.

[22] A. Kibaroglu, E. Eksioglu-Demiralp, T. Akoglu, and H. Direskeneli, "T and NK cell subset changes with microbial extracts 
and human HSP60-derived peptides in Behcet's disease," Clinical and Experimental Rheumatology, vol. 22, no. 4, supplement 34, pp. S59-S63, 2004.

[23] T. Sakane, M. Takeno, N. Suzuki, and G. Inaba, "Behcet's disease," The New England Journal of Medicine, vol. 341, no. 17, pp. 1284-1291, 1999.

[24] M. Suzuki-Krokawa and N. Suzuki, "Behcet's disease," Clinical and Experimental Medicine, vol. 3, pp. 10-20, 2004.

[25] D. Bang, K. H. Yoon, H. G. Chung, E. H. Choi, E. S. Lee, and S. Lee, "Epidemiological and clinical features of Behcet's disease in Korea," Yonsei Medical Journal, vol. 38, no. 6, pp. 428-436, 1997.

[26] J. A. Ship, "Recurrent aphthous stomatitis. An update," Oral Surgery, Oral Medicine, Oral Pathology, Oral Radiology, and Endodontics, vol. 81, no. 2, pp. 141-147, 1996.

[27] F. Kaneko, "Behcet's disease," in A Color Atlas of DermatoImmunohistology, H. Ueki and H. Yaoita, Eds., pp. 84-85, Wolfe Medical Publication, London, UK, 1989.

[28] B. Lipschutz, "Ulcer vulvae acutum," in Handbuch der Haut und Geschl, J. Jadassohn, Ed., vol. 21, pp. 392-414, Spriger, Berlin, Germany, 1927.

[29] A. Lampert, H. Assier-Bonnet, B. Chevallier, T. Clerici, and P. Saiag, "Lipschutz's genital ulceration: a manifestation of Epstein-Barr virus primary infection," The British Journal of Dermatology, vol. 135, no. 4, pp. 663-665, 1996.

[30] S. Lee, D. Bang, and E. S. Lee, "Behcet's disease," in The 3rd List of Publication on Behcet's Disease. 1995-2002, pp. 27-49, Yonsei University College of Medicine, Seoul, Republic of Korea; Ajou University School of Medicine, Suwon, Republic of Korea, 2003.

[31] S. Haim, J. D. Sobel, R. Friedman Birnbaum, and C. Lichtig, "Histological and direct immunofluorescence study of cutaneous hyperreactivity in Behcet's disease," The British Journal of Dermatology, vol. 95, no. 6, pp. 631-636, 1976.

[32] J. L. Jorizzo, J. L. Abernethy, W. L. White et al., "Mucocutaneous criteria for the diagnosis of Behcet's disease: an analysis of clinicopathologic data from multiple international centers," Journal of the American Academy of Dermatology, vol. 32, no. 6, pp. 968-976, 1995.

[33] H. Serhat Inaloz, C. Evereklioglu, B. Unal, N. Kirtak, A. Eralp, and S. S. Inaloz, "The significance of immunohistochemistry in the skin pathergy reaction of patients with Behcet's syndrome," Journal of the European Academy of Dermatology and Venereology, vol. 18, no. 1, pp. 56-61, 2004.

[34] S. Cho, Z. Zheng, S. Cho et al., "Both the sera of patients with Behcet's disease and Streptococcus sanguis stimulate membrane expression of hnRNP A2/B1 in endothelial cells," Scandinavian Journal of Rheumatology, vol. 42, no. 3, pp. 241-246, 2013.

[35] S. B. Cho, Z. Zheng, K. J. Ahn et al., "Serum IgA reactivity against GroEL of Streptococcus sanguinis and human heterogeneous nuclear ribonucleoprotein $\mathrm{A} 2 / \mathrm{B} 1$ in patients with Behcet's disease," The British Journal of Dermatology, vol. 168, no. 5, pp. 977-983, 2013.

[36] International Study Group for Behcet's Disease, "Criteria for diagnosis of Behcet's disease," The Lancet, vol. 335, no. 8697, pp. 1078-1080, 1990.

[37] H. Yazici, Y. Tuzun, H. Pazarli, B. Yalcin, S. Yurdakul, and A. Muftuoglu, "The combined use of HLA-B5 and the pathergy test as diagnostic markers of Behcet's disease in Turkey," Journal of Rheumatology, vol. 7, no. 2, pp. 206-210, 1980.

[38] F. Davatchi, C. Chams-Davatchi, F. Shahram et al., "Pathergy test in Behcet's disease: change in incidence over the time," APLAR Journal of Rheumatology, vol. 10, no. 4, pp. 333-335, 2007.
[39] P. G. Davies, J. N. Fordham, J. R. Kirwan, C. G. Barnes, and W. J. Dinning, "The pathergy test and Behcet's syndrome in Britain," Annals of the Rheumatic Diseases, vol. 43, no. 1, pp. 70-73, 1984.

[40] R. Friedman-Birnbaum, R. Bergman, and E. Aizen, "Sensitivity and specificity of pathergy test results in Israeli patients with Behcet's disease," Cutis, vol. 45, no. 4, pp. 261-264, 1990.

[41] I. Fresko, H. Yazici, M. Bayramicli, S. Yurdakul, and C. Mat, "Effect of surgical cleaning of the skin on the pathergy phenomenon in Behcet's syndrome," Annals of the Rheumatic Diseases, vol. 52, no. 8, pp. 619-620, 1993.

[42] A. Togashi, S. Saito, F. Kaneko, K. Nakamura, and N. Oyama, "Skin prick test with self-saliva in patients with oral aphthoses: a new diagnostic pathergy for behcet's disease and recurrent aphthosis," Inflammation and Allergy - Drug Targets, vol. 10, no. 3, pp. 164-170, 2011.

[43] M. Tojo, H. Yanagihori, X. Zheng et al., "Bes-1 DNA fragment encoding streptococcal antigen in skin lesions from patients with Behcet's disease," Journal of Applied Research, vol. 3, no. 3, pp. 232-238, 2003.

[44] N. Mizuki, H. Inoko, and S. Ohno, "Molecular genetics (HLA) of Behcet's disease," in Behcet's Disease-A Guide to Its Clinical Understanding, S. Lee, D. Bang, E.-S. Lee, and S. Sohn, Eds., pp. 87-100, Springer, New York, NY, USA, 2001.

[45] H. Yasuoka, Y. Okazaki, Y. Kawakami et al., "Autoreactive CD8+ cytotoxic T lymphocytes to major histocompatibility complex class I chain-related gene A in patients with Behcet's disease," Arthritis and Rheumatism, vol. 50, no. 11, pp. 3658-3662, 2004.

[46] J. Seo, J. S. Park, J. H. Nam et al., "Association of CD94/NKG2A, CD94/NKG2C, and its ligand HLA-E polymorphisms with Behcet's disease," Tissue Antigens, vol. 70, no. 4, pp. 307-313, 2007.

[47] F. Kaneko, Y. Takahashi, and R. Muramatsu, "Natural killer cell numbers and function in peripheral lymphoid cells in Behcet's disease," The British Journal of Dermatology, vol. 113, no. 3, pp. 313-318, 1985.

[48] J. Shimizu, K. Takai, N. Fujiwara et al., "Excessive CD4+ T cells co-expressing interleukin-17 and interferon- $\gamma$ in patients with Behcet's disease," Clinical and Experimental Immunology, vol. 168, no. 1, pp. 68-74, 2012.

[49] F. Kaneko, N. Oyama, H. Yanagihori, E. Isogai, K. Yokota, and K. Oguma, "The role of streptococcal hypersensitivity in the pathogenesis of Behcet's disease," European Journal of Dermatology, vol. 18, no. 5, pp. 489-498, 2008.

[50] F. Kaneko, A. Togashi, S. Saito et al., "Behcet's disease (Adamantiades-Behcet's disease)," Clinical and Developmental Immunology, vol. 2011, Article ID 681956, 7 pages, 2011.

[51] H. Yanagihori, N. Oyama, K. Nakamura, N. Mizuki, K. Oguma, and F. Kaneko, "Role of IL-12B promoter polymorphism in Adamantiades-Behcet's disease susceptibility: an involvement of Th1 immunoreactivity against Streptococcus sanguinis antigen," Journal of Investigative Dermatology, vol. 126, no. 7, pp. 1534-1540, 2006.

[52] E. Isogai, H. Isogai, S. Kotake et al., "Antibody cross reactivity from sera of patients with behcet's disease with synthetic peptides that have homologies with proteins from Streptococcus sanguis," Journal of Applied Research, vol. 2, no. 3, pp. 1-7, 2002.

[53] E. Isogai, H. Isogai, S. Kotake, S. Ohno, K. Kimura, and K. Oguma, "Role of Streptococcus sanguis and traumatic factors in Behcet's disease," Journal of Applied Research, vol. 3, no. 1, pp. 64-75, 2003.

[54] K. Yoshikawa, S. Kotake, T. Kubota, K. Kimura, E. Isogai, and N. Fujii, "Cloning and sequencing of BES-1 gene encoding the 
immunogenic antigen of Streptococcus sanguis KTH-1 isolated from the patients with Behcet's disease," Zentralblatt fur Bakteriologie, vol. 287, no. 4, pp. 449-460, 1998.

[55] M. Tojo, X. Zheng, H. Yanagihori et al., "Detection of herpes virus genomes in skin lesions from patients with Behcet's disease and other related inflammatory diseases," Acta DermatoVenereologica, vol. 83, no. 2, pp. 124-127, 2003.

[56] M. Xiang, L. Zhou, Y. Peng, R. L. Eddy, T. B. Shows, and J. Nathans, "Brn-3b: a POU domain gene expressed in a subset of retinal ganglion cells," Neuron, vol. 11, no. 4, pp. 689-701, 1993.

[57] A. Kulaber, I. Tugal-Tutkun, S. P. Yentür et al., "Pro-inflammatory cellular immune response in Behcet's disease," Rheumatology International, vol. 27, no. 12, pp. 1113-1118, 2007.

[58] E. Deniz, U. Guc, N. Buyukbabani, and A. Gul, "HSP 60 expression in recurrent oral ulcerations of Behet's disease," Oral Surgery, Oral Medicine, Oral Pathology, Oral Radiology and Endodontology, vol. 110, no. 2, pp. 196-200, 2010.

[59] U. Zugel and H. E. Kaufman, "Role of heat shock proteins in protection from and pathogenesis of infectious diseases," Clinical Microbiology Reviews, vol. 12, pp. 19-39, 1999.

[60] M. Stanford, T. Whittall, L. A. Bergmeier et al., "Oral tolerization with peptide 336-351 linked to cholera toxin B subunit in preventing relapses of uveitis in Behcet's disease," Clinical and Experimental Immunology, vol. 137, no. 1, pp. 201-208, 2004.

[61] K. Oguma, R. Shin, and K. Yokota, "Studies on immunological responses by bacterial antigens in Behcet's disease," in Report of the Research Group for Behcet's Disesae Organized by the Japanese Ministry of Health, Lavour and Welfare 2006-2007, pp. 31-33, 2008 (Japanese).

[62] F. Kaneko, A. Togashi, E. Nomura et al., "Role of heat shock protein derived from Streptococcus sanguinis in Behcet's disease," Journal of Medical Microbiology and Diagnosis, S2, 2012.

[63] K. A. Zarember and P. J. Godowski, "Tissue expression of human toll-like receptors and differential regulation of toll-like receptor mRNAs in leukocytes in response to microbes, their products, and cytokines," Journal of Immunology, vol. 168, no. 2 , pp. 554-561, 2002.

[64] V. Hornung, S. Rothenfusser, S. Britsch et al., "Quantitative expression of toll-like receptor 1-10 mRNA in cellular subsets of human peripheral blood mononuclear cells and sensitivity to CpG oligodeoxynucleotides," Journal of Immunology, vol. 168, no. 9, pp. 4531-4537, 2002.

[65] S. Yavuz, Y. Elbir, A. Tulunay, E. Eksioglu-Demiralp, and H. Direskeneli, "Differential expression of toll-like receptor 6 on granulocytes and monocytes implicates the role of microorganisms in Behcet's disease etiopathogenesis," Rheumatology International, vol. 28, no. 5, pp. 401-406, 2008.

[66] O. Durranni, G. R. Wallace, J. Hamburger et al., "Toll-like receptors (TLRs) expression in oral ulcer biopsies from Behcet's disease (BD) patients: a role for the innate immune system in BD," Clinical and Experimental Rheumatology, vol. 22, supplement 34, p. S-93, 2004.

[67] S. W. Yi, E. H. Kim, H. Y. Kang, Y. C. Kim, and E. S. Lee, "Erythema nodosum: clinicopathologic correlations and their use in differential diagnosis," Yonsei Medical Journal, vol. 48, no. 4, pp. 601-608, 2007.

[68] T. Iikunur, U. Pabuccuoglu, C. Akin, B. Lebe, and A. T. Gunes, "Histopathologic and direct immunofluorescence findings of the papulopustular lesions in Behcet's disesase," European Journal of Dermatology, vol. 16, pp. 146-150, 2006.

[69] M. Çalgüneri, I. Ertenli, S. Kiraz, M. Erman, and I. Çelik, "Effect of prophylactic benzathine penicillin on mucocutaneous symptoms of Behcet's disease," Dermatology, vol. 192, no. 2, pp. 125-128, 1996.

[70] G. Mumcu, N. Inanc, S. Yavuz, and H. Direskeneli, "The role of infectious agents in the pathogenesis, clinical manifestations and treatment strategies in Behcet's disease," Clinical and Experimental Rheumatology, vol. 25, no. 4, pp. S27-S33, 2007. 

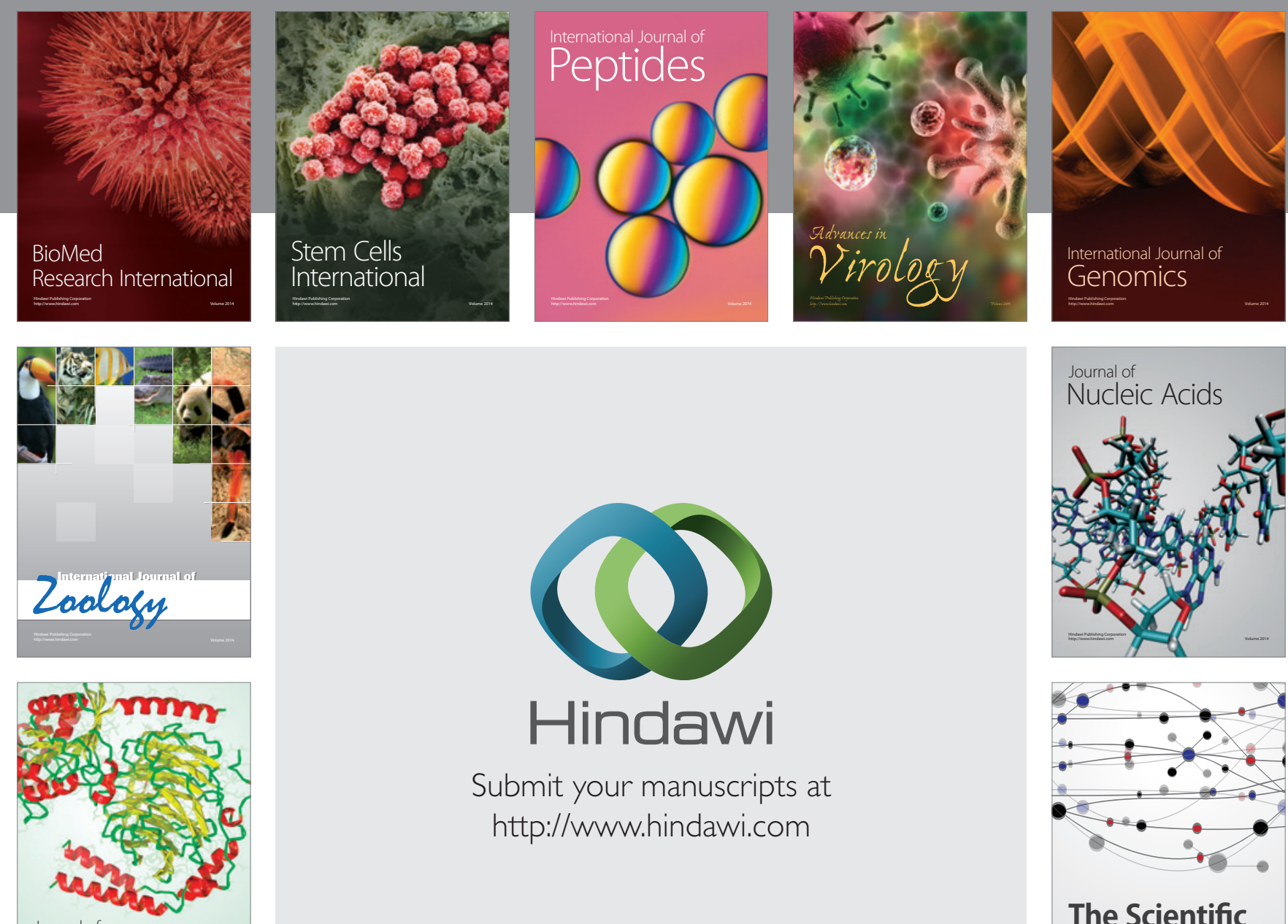

Submit your manuscripts at

http://www.hindawi.com

Journal of
Signal Transduction
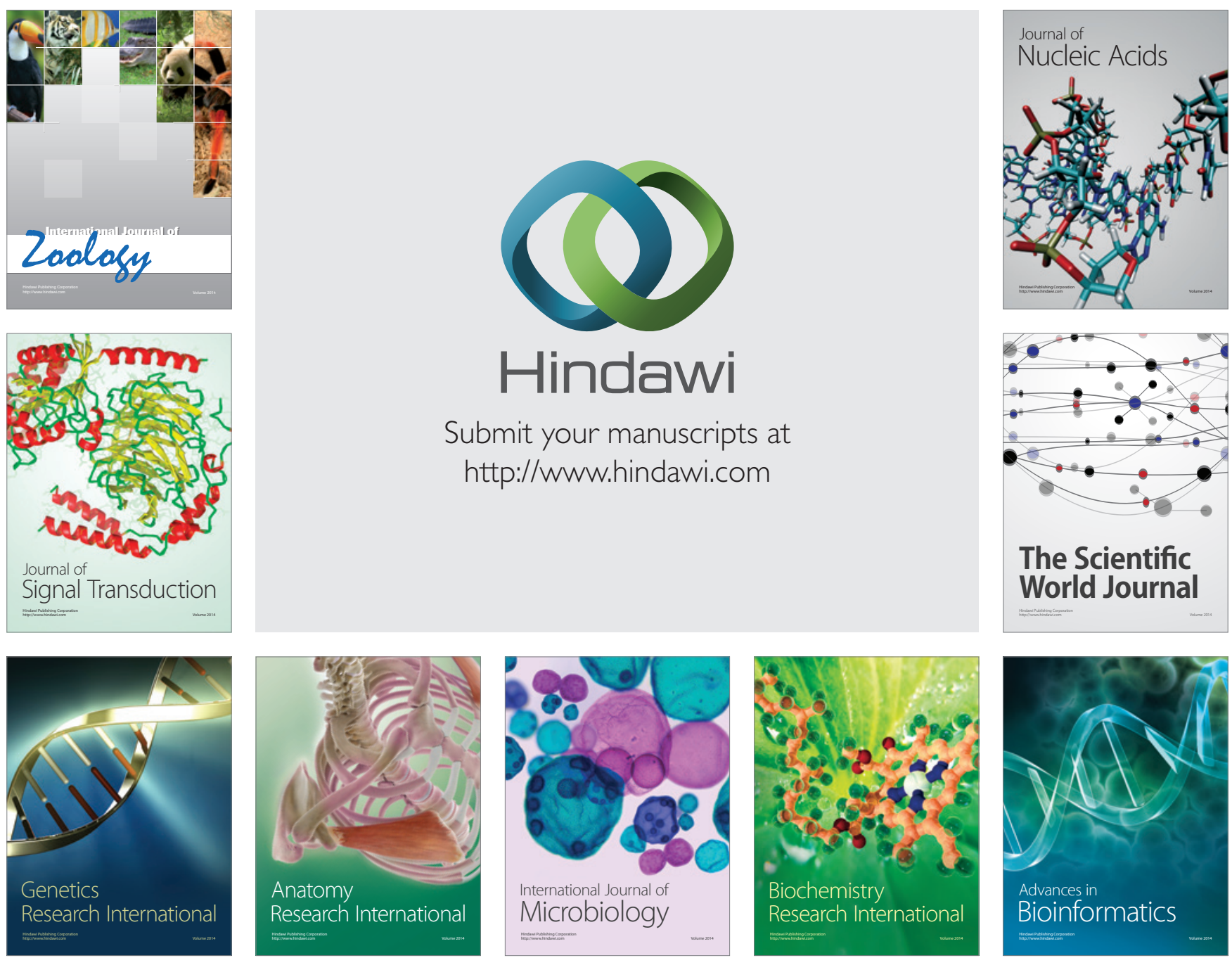

The Scientific World Journal
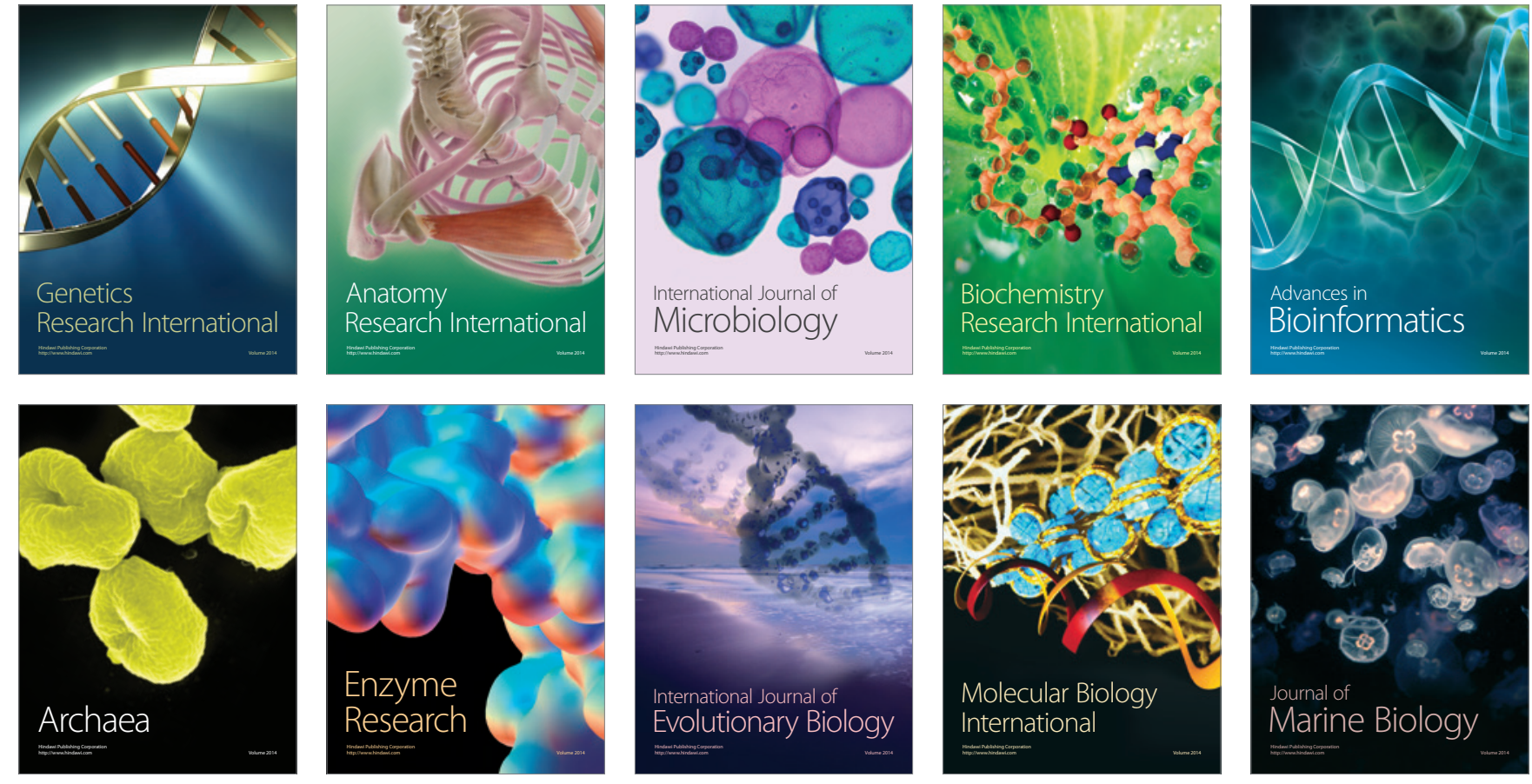